Santa Clara University

Scholar Commons

$10-2014$

\title{
Mil y una muertes de Sergio Ramírez y los fantasmas de la construcción nacional nicaragüense
}

Alberto Ribas-Casasayas

Santa Clara University, aribascasasayas@scu.edu

Follow this and additional works at: https://scholarcommons.scu.edu/mod_lang_lit

Part of the Modern Languages Commons, Modern Literature Commons, and the Spanish Literature Commons

\section{Recommended Citation}

Ribas-Casasayas, Alberto. "Mil Y Una Muertes De Sergio Ramírez Y Los Fantasmas De La Construcción Nacional Nicaragüense." Revista De Estudios Hispánicos 48.3 (2014): 493-517.

Copyright (C 2014 Washington University in St. Louis. Reprinted with permission. http://rll.wustl.edu/reh http://muse.jhu.edu/journals/revista_de_estudios_hispánicos

This Article is brought to you for free and open access by the College of Arts \& Sciences at Scholar Commons. It has been accepted for inclusion in Modern Languages \& Literature by an authorized administrator of Scholar Commons. For more information, please contact rscroggin@scu.edu. 


\title{
Mil y una muertes de Sergio Ramírez y los fantasmas de la construcción nacional nicaragüense
}

\begin{abstract}
Este artículo analiza la novela Mil y una muertes del nicaragüense Sergio Ramirez con un énfasis en los temas de lo fantasmal, fotografia e identidad nacional. Partiendo de un cuestionamiento de la "internacionalización" de la temática novelistica de Ramirez, este articulo describe cómo el personaje principal de la novela, el fotógrafo Castellón, evoca fracasos personales y estéticos que por otra parte alumbran condiciones de infraciudadania de cuerpos sujetos a la merced del estado y situados al borde de la catástrofe. Al mismo tiempo, la frustración vital de Castellón es eco de una frustración simbólica más amplia, la de Nicaragua como proyecto nacional basado en las aspiraciones del canal interoceánico y la inversión extranjera. El fracaso artístico de Castellón es un correlato del fracaso moral de una generación previa de politicos inconscientes de las contradicciones de cualquier proyecto de estado-nación moderno o de articulación nacional asentado sobre las bases de la exclusión.
\end{abstract}

Uno de los argumentos más repetidos a propósito de Mil y una muertes, y corroborado en parte por su autor, es que en esta novela Sergio Ramírez abandona el carácter "local" de sus exploraciones de la dictadura somocista en Nicaragua y se abre a temáticas más amplias de alcance internacional (Vargas; Urbina; Ramírez citado en Colín). Es cierto que las aventuras de sus personajes principales en Polonia, Francia y Mallorca y la presencia reiterada de figuras claves de la cultura europea desde el romanticismo tardío hasta principios del novecientos dan a Mil y una muertes un carácter euroconvergente. Sin embargo, la incorporación de Nicaragua como ente soberano en el panorama geopolítico internacional constituye uno de sus temas fundamentales. La novela se articula en función de dos narraciones paralelas que comienzan con sendas misiones diplomáticas nicaragüenses en Europa: Sergio Ramírez en 
Polonia hacia el final de la Guerra Fría y Francisco Castellón en Francia a mediados del siglo XIX. Ambos personajes están conectados por la voz "de ultratumba" del fotógrafo Francisco Castellón (312), hijo natural del Castellón político y objeto de la búsqueda del escritor.

Las visiones futuristas de los políticos centroamericanos del siglo XIX y su frustración ante la declarada inexistencia de Nicaragua en el plano político internacional encuentran su eco en las imágenes de lo etéreo y lo cadavérico en que abunda esta novela, así como en la voz fantasmal de Castellón, perdida y marginal entre los grandes de la historia y el arte europeo modernos. En las próximas páginas analizaré la constelación de significantes de lo espectral en Mil y una muertes, a fin de mostrar cómo el fantasma de Castellón evoca fracasos personales y estéticos que son a su vez el correlato de un fracaso histórico más amplio en las aspiraciones de la generación previa.

Mil y una muertes trata sobre una búsqueda que se inicia a finales de los ochenta, cuando Sergio Ramírez visita Polonia en calidad de vicepresidente del estado sandinista y se encuentra, de manera fortuita, con una exposición conmemorativa sobre un tal "fotógrafo Castellón" (30), un nicaragüense que pasó su vejez en Polonia y terminó en el campo de concentración de Mauthausen. Sergio Ramírez se interesa por la presencia de un compatriota suyo en un momento tan crítico de la historia occidental e inicia una investigación sobre esta figura. La búsqueda de Ramírez se alterna con la narración "de ultratumba" del propio fotógrafo. Este revela ser hijo de la violación de Catherine, princesa de Mosquitia (protectorado británico en la costa atlántica de la actual Nicaragua) por el presidente Francisco Castellón, de infausto recuerdo en la imaginación nacional por haber pedido la intervención del filibustero William Walker en 1855. Años después el joven recibe el patrocinio de un decadente Napoleón III, ya olvidado de sus antiguos intereses americanos y a punto de confrontar su debacle ante Prusia. En París aprende el naciente oficio de la fotografía a través del cual se cruza con algunos personajes principales de la historia cultural europea como George Sand, Flaubert y Turguénev. El fotógrafo pasa a continuación a Mallorca, donde trata con el archiduque Luis Salvador de Austria y con un Rubén Darío alcoholizado y ya disminuido en sus facultades. Se casa con Teresa Segura, una xueta o descendiente de judíos conversos de Mallorca. Unos años después vive en Varsovia con su hija Catalina y su esposo, un judío polaco. A comienzos de la II Guerra Mundial, Catalina y su esposo son asesinados por los nazis en Varsovia mientras que el 
fotógrafo Castellón queda al servicio de un oficial de las SS en el campo de concentración de Mauthausen, velando por la supervivencia de su nieto Rubén y la propia. Solo en el encuentro final de la investigación de Sergio Ramírez, este Rubén Bonnin, quien regenta una decrépita tienda de mística new age en el antiguo barrio xueta de Palma (Ciudad de Mallorca), se reivindica a sí mismo como el auténtico narrador de la historia (incluyendo, posiblemente, la narración de la búsqueda del propio Ramírez).

Al referirse a Rubén Bonnin como "amanuense" de unas "memorias de ultratumba", Ramírez cierra Mil y una muertes con una alusión contemporánea al topos del manuscrito encontrado, encontrándonos aquí ante una suerte de voz oracular surgida de entre los muertos (312). Es la voz del fotógrafo Castellón, quien nos revela peculiaridades de un pasado oculto que arrojan una nueva luz sobre el presente. Así, Ramírez recupera una figura, el muerto que narra su propia historia, que ha tenido ilustres exponentes en literatura latinoamericana ( $\mathrm{La}$ amortajada de María Luisa Bombal o Pedro Páramo de Juan Rulfo) y que, aún en ańos recientes, había sido recuperada en novelas escritas cerca del quinto centenario de la llegada de los españoles a América (La mujer habitada de Gioconda Belli y El naranjo de Carlos Fuentes). Mencionaremos al respecto la asaz recordada reflexión derridiana del fantasma como (re)aparecido o revenant al que se le debe una bienvenida en aras de la justicia (Derrida 277-78). En otro importante libro, Ghostly Matters, la socióloga Avery Gordon comentó cómo los discursos sociológicos, tal como los conocemos, no cuentan una historia completa de las pérdidas y ausencias causadas por un trauma histórico (8). El discurso social no puede dar cuenta de ello, en parte, porque los humanos estamos condicionados para prestar atención a lo visible, lo presente, el evento, más que a lo invisible, lo ausente, o lo no ocurrente (Gordon 21-22). Desde una perspectiva más literaria, Jacob Bennett y Nicholas Royle apuntan que lo Unheimlich o extraño (en su acepción psicoanalítica) de la ficción reside en la misma naturaleza de su medio, el texto, donde lo aparicional y lo no aparicional están hechos del mismo material textual y son, por ende, indistinguibles (137). Punter, a su vez, destaca que el acto de lectura enfatiza lo fantasmal de la comunicación de sentido más allá de su soporte material, así como su aspecto relacional con una voz que rescata el pasado en una modalidad no autoritativa o historiográfica sino admonitoria y profética (260-61). 
El fantasma, en suma, se ha convertido en la literatura contemporánea en un tropo que viene a representar las voces no consignadas por el registro histórico. Además, y como mostraré en las próximas páginas, Mil y una muertes manifiesta diversas dimensiones de lo fantasmal a través de temas como: la voz del propio fotógrafo Castellón, voz narrativa de ultratumba, oracular, que revela aspectos sin examinar del pasado nacional a la vez que es revelado él mismo como expresión del fracaso de un proyecto histórico; la íntima conexión entre fotografía, inmovilidad y muerte; la mezcla de evocación y mistificación sobre iconos literarios y visuales paradigmáticos de la historia cultural de Latinoamérica y de Occidente en general; o Nicaragua como fantasma en la América postcolonial, que pugna por tomar cuerpo en el escenario politico internacional del siglo XIX o en la memoria del presente. Estudiaré asimismo cómo se entremezcla con lo espectral el ámbito conceptual de la fotografía, particularmente en su representación de estados límite o de transición entre la vida y la muerte. La visión de la fotografía en esta novela está en deuda con Barthes y Sontag pero también manifiesta la presencia de sujetos excluidos, forzados a existir en los límites de la catástrofe. Esta exclusión recontextualiza las decepciones y fracasos del discurso nacionalista liberal encarnado por Francisco Castellón en el marco de la globalidad contemporánea.

\section{El fotógrafo Castellón, fantasma del fracaso histórico}

La historia de Mil y una muertes se articula a través de dos narradores. En lo tocante a la espectralidad, nos interesa el fotógrafo Castellón: puede ser una voz "de ultratumba", según la describe Ramírez o simplemente un artificio de su pintoresco nieto Rubén (312). En cualquier caso, es la propia búsqueda de Ramírez lo que da lugar a la aparición del fantasma como acto narrativo. "Alguien me anda buscando" son las primeras palabras de la narración de Castellón; se refiere a Ramírez y, por extensión, al lector (53). No es este, por lo tanto, un fantasma que asedie el presente en busca de una reparación, sino que se corresponde más con la lectura psicoanalítica de Abraham y Torok, quienes veían al fantasma como presencia de un antepasado muerto en la psique de su descendencia viviente que insiste en evitar que ciertos secretos sobre el pasado familiar o transgeneracional surjan a la luz (L'écorce et le noyau). La actitud del fotógrafo, de "desdén" ante 
la posteridad según se refleja en su autorretrato, y el mandato “ ¡No me despiertes!" del "Epitafio II" de Xavier Villaurrutia que encabeza el texto evocan la actitud renuente del fantasma a ser rescatado del olvido de la historia (Ramírez, Mil y una 144, 11; Villaurrutia 96). Es el alter ego del autor, Ramírez, quien hurga en el pasado, persiste en rescatar y actualizar una figura olvidada ("No deja de seguirme seduciendo como personaje que puede ser de una novela") y es su mirada lo que genera que a su vez este fantasma devuelva su propia mirada al presente y le dirija su narración (240).

El propio Castellón se ve rodeado de un halo de exotización y misterio. En principio el fotógrafo elude hablar de su nacionalidad (44), aunque en Europa suponen que tiene ascendencia norteafricana y lo exotizan: Rubén Darío menciona que tiene "uno de esos rostros misteriosos", ignorando entonces que es nicaragüense como él, para George Sand evoca "aquellos príncipes indígenas del Amazonas" y el archiduque Luis Salvador de nuevo lo llama "príncipe de las selvas ignotas" (18, $102,242)$. Flaubert, en cambio, lo asocia con un sirviente de los bańos públicos de Egipto, en una evocación mórbida que mezcla homoerotismo con el concepto de belleza corrompida que recurre en la novela:

su pelo suelto en sortijas, que brilla como ungido de áloe, le recuerda a Ahmed, el sirviente de los baños públicos del Cairo, como si aquel fantasma de ayer, deshecho en sudor, volviera a materializarse entre los mismos vapores cálidos, y piensa: si no lo ha matado el escorbuto tendrá ahora más de cuarenta años, un viejo ya en aquel clima mefítico que corrompe la belleza bajo sus bocanadas ardientes. (102)

Su exotización precisamente subraya que el fotógrafo es una figura condenada a la marginalidad desde el principio: hijo mestizo de un criollo y una miskita, su participación en sucesivos triángulos amorosos terminará asociándolo con Catalina Segura y por extensión con los xuetes o descendientes de judíos conversos de Mallorca. En consecuencia, el Otro de América Latina termina, al cruzar del Atlántico, identificado con un Otro característico de la escena europea, el judío.

La exotización étnico-nacional del fotógrafo Castellón se manifiesta en paralelo con su marginalidad artística. Los textos espúreos de Darío y Vargas Vila en la novela representan al fotógrafo como figura subordinada que acompaña a los poderosos en la creación de las representaciones de su poder, como un adlátere marginal apegado a artistas de mayor talento que el suyo gozando sus excentricidades de manera oportunista. La relación artística del fotógrafo Castellón con Rubén 
Darío es equivalente a la relación política que tuvo su padre Francisco Castellón con Napoleón III. Francisco Castellón es el político menor, subordinado, en la expectativa de una intervención o una inversión que, en su imaginación, dé cuerpo a la identidad de Nicaragua en el panorama político internacional. A su vez, su hijo, el fotógrafo Castellón, es el subproducto de la maquinación quimérica de un roi savant (Frederick) en un protectorado del imperio británico, producto de la unión de dos cuerpos políticos (un protectorado dependiente, una nación sin entidad), la unión entre dos grupos étnicos que, aún siendo parte integrante de un mismo proyecto nacional, carecen de un espacio de reconocimiento mutuo. La filiación del fotógrafo viene a encarnar el fracaso de las aspiraciones políticas del liberalismo centroamericano: está destinado a repetir el destino de su padre Francisco, quien terminó, como el sueño del canal, convertido en un fantasma político, sus esperanzas desvanecidas "en esa impotencia nostálgica en que vienen a quedar las intimidades con los grandes de la tierra” (180).

Si Francisco Castellón fallece como fantasma político, su hijo natural fallece como fantasma artístico, padeciendo la ignominia de trabajar al servicio de los nazis en Mauthausen a cambio de su supervivencia y la de su nieto. En su narración, el fotógrafo Castellón se define a sí mismo como "fotógrafo mediocre, un aprendiz toda la vida" que muere cada día un poco de miedo (277). En una revisión del tema de las mille personnes de Roland Barthes, Castellón habla de sí como un hombre que ha vivido múltiples muertes asediado por el miedo (Barthes 42, 131; Ramírez, Mil y una 275-76). Magdalena Perkowska observa cómo la novela enfatiza esta duplicidad entre la grandeza de la pose oficial de figuras institucionales y artísticas "y las flaquezas de la intimidad o el fondo invisible de sus almas" ("Fotografía"). En efecto, la novela parece empañada de una actitud de sospecha respecto al posicionamiento moral del artista y, por extensión, del intelectual. Sin embargo, Luciana Namorato previene que la novela hace hincapié "en la conciencia de que todo personaje-basado en un personaje histórico o no-posee una vida exterior a la narración" (193). Vale la pena considerar desde esta óptica la censura moral de Dominik (el guía de Ramírez en Polonia) sobre la actitud sumisa del polaco Chopin ante el imperio ruso al sentenciar que su "merecimiento [artístico] choca con lo impropio de su conducta” (Ramírez, Mil y una 47). Pesa sobre los artistas el fantasma del acomodacionismo político, y sin embargo el contraste entre Chopin 
y Castellón, entre la gran figura y el artista olvidado, pone de manifiesto lo movedizo de la censura moral de Dominik: según este, el genio artístico debe ir acompañado de una suerte de personalidad política y ética igual de fuerte, máxime cuando se le considera representativo de la nación, aunque su actividad se produzca en el marco de procesos políticos que tal vez sobrepasen sus poderes prácticos. Visto desde otro ángulo, Dominik proyecta una responsabilidad política sobre el artista, sobre sujetos que en su época tal vez sean más o menos sobresalientes pero que no siempre gozan de las protecciones efectivas del ejercicio del poder y cuyas atribuciones virtuales en tanto que representantes de un genio nacional suelen ser investidas in morte por el propio edificio político-cultural nacional. La ignominia de Castellón, siendo la de un artista menor, manifiesta la cuestión de forma un tanto más prosaica: este imperativo moderno de que el artista actúe como conciencia públi$\mathrm{ca}$, ¿puede sostenerse en vista de los escasos medios materiales con que éste cuenta para defenderse, sobrevivir o ser materialmente útil?

Queda la cuestión de la fiabilidad de la narración misma. El fotógrafo Castellón habla de "esa versión ofrecida por un individuo ruin y toda la vida envidioso del brillo ajeno", en aparente referencia al desdeñoso juicio de Vargas Vila sobre Rubén Darío y su entorno en Mallorca (282). Esta duda proyecta otra sobre la propia narración: si ese "individuo ruin" no será una confesión del propio Rubén narrando y proyectando esa visión tan poco caritativa de su abuelo fotógrafo ("Lo que tuve es miedo, el miedo que suele encubrirse bajo esa falsa máscara que también sirve para ocultar la mediocridad, y las frustraciones"), que bien podría ser producto del resentimiento del nieto (277). ¿¿Se reconoce Rubén a sí mismo como ese "individuo ruin"? Como apunta Namorato, "[e]s significativo que, en el último capítulo del relato, el testimonio de Rubén, el nieto de Castellón, contradiga la versión de su abuelo. Se sugiere, de este modo, que las informaciones recabadas sobre el título Mil y una muertes se encuentran lejos de hacer justicia a la riqueza de la vida del fotógrafo" (182). Hay algo de entereza y persistencia en cómo el fotógrafo soporta los vaivenes del destino, las humillaciones que padece ante Luis Salvador por su amante Wenceslao y por su mujer Catalina, ante la sociedad polaca y el carnicero Bonnin por su hija Teresa, y, en última instancia, colaborando con los nazis para asegurar la supervivencia de su nieto Rubén. En cierto modo, el drama de la existencia del fotógrafo es equiparable a los intentos futiles de su tío, el rey Frederick, 
o las humillaciones padecidas por su padre, Francisco Castellón, por dar una salida viable al proyecto nacional y político nicaragüense. $\mathrm{La}$ resurrección del espectro del fotógrafo Castellón, el artista mediocre, por su nieto Rubén, es producto de un insuperable resentimiento hacia el pasado. En este contexto, la imagen de Castellón arrollado por una avalancha "de piedras, lodo, troncos descuajados" al final de la novela constituye el imperativo final de construir algo que supere la imagen apocalíptica de Latinoamérica que se ha asentado en las letras del cambio de siglo (323). Un llamado al que deberán responder generaciones futuras, libres del espectro de la derrota.

\section{Fotógrafos y carniceros: el filo de la objetividad}

El contraste entre la espectralidad de la fotografía y sus aspiraciones a la representación objetiva del entorno visible constituyen objetos centrales de la indagación narrativa de Mil y una muertes. La novela abunda en el carácter fantasmal de la fotografía en blanco y negro: desvaída por el paso del tiempo, fijada en un instante agotado que persiste en el presente merced a su reproducción mecánica, evoca una permanencia aurática de lo ausente, un estar-ahí distante. Diversos episodios de la novela evocan la interpretación barthesiana del retrato fotográfico, según la cual el sujeto vivo en el encuadre experimenta con el disparo una "microexperiencia de la muerte" y se espectraliza al contemplar a través del retrato a un espectador futuro, quien reconoce en la ausencia presente del sujeto del retrato su propia mortalidad, lo que Barthes llamaba "ese signo imperioso de mi muerte futura" (Barthes 46; 168; ver también cap. 38).

Perkowska ya ha analizado el rol de la imagen estática en la novela de Ramírez como acto social concreto "en el que se activan relaciones de poder que pueden adquirir visos de predación", una relación de poder/conocimiento en la que el objeto de representación se ve apropiado por otro agente ("Fotografía")'. Ciertamente, Mil y una muertes se apuntala considerablemente sobre las lecturas de Barthes y Sontag sobre el género fotográfico, según lo evidencia el propio Ramírez en su artículo "El niño, el buitre y el cerdo". Sontag le impone responsabilidades al fotógrafo: el registro compele a la repetición del horror. Quien registra es corresponsable de los horrores futuros que busquen nuestra 
atención. Según esta lectura, por ejemplo, los medios serían los corresponsables de la búsqueda de quince minutos de fama de un mass shooter en Estados Unidos. Pero para Ramírez, la responsabilidad de fotógrafos $\mathrm{y}$ artistas es registrar el horror, lo bello y lo sublime que presencien. El registro del horror puede tener "consecuencias de advertencia acerca de los abismos de injusticia que en lugar de cerrarse, se abren cada vez más" (Ramírez, "El nińo").

Que Ramírez justifique el acto de disparar la foto no significa que no sea consciente de las duplicidades morales del acto de registrarla. Tal es el caso, por ejemplo, de cuando Castellón registra fotográfcamente el asesinato de su hija y su yerno a manos de los nazis (51). En el acto de tomar esta última foto, el artista sacrifica su vinculación emocional con su material en aras de un acto testimonial. Pero Mil y una muertes precisamente trata de cuestionar las trampas éticas del posicionamiento objetivista. En la novela, Maxime du Camp, pionero francés del arte fotográfico y antiguo compañero de aventuras mediterráneas de Flaubert, introduce la noción de "belleza contaminada" como objeción a las posiciones de Flaubert y Primoli sobre la neutralidad del "ojo del artista" $(154,150)$. Du Camp resalta la hipocresía del objetivismo realista al contrastar el distanciamiento de Flaubert del mundo que retrata con su "crimen premeditado" de contagiarle la sífilis a una prostituta en Alejandría (150). La novela contrapone las pretensiones científicas del objetivismo realista y el empirismo positivista a la capacidad y oportunidades reales de causar perjuicios que ostentan los individuos privilegiados en el contexto sociopolítico de un mundo colonizado. La objetividad se resume en la imagen del cuchillo. Como la navaja de Occam, la objetividad tiene filo, en este caso, doble: "un instrumento único que sirve para desollar la carne y sacar las vísceras, y a la vez para desmontar la piedra preciosa" (154). Todo evento estético, y por ende todo testimonio fotográfico, está inmerso en una duplicidad ética y estética.

El mentor del fotógrafo Castellón, el conde Giuseppe Primoli, aboga en cambio por el distanciamiento científico: "[E]l artista es un patólogo que conservará las piezas disecadas en los frascos de formol de su memoria" (154). Ramírez se sirve de la figura de Primoli para reelaborar una versión de la teoría barthesiana sobre el sujeto como suma de instantes fotográficos (Barthes 42-43, 126). El personaje se compone de "diferentes poses", "diferentes situaciones" y "diferentes 
compañías", de modo que la foto comunica la diversidad de personas a lo largo de los ańos, mientras que la familiaridad crea "una falsa imagen única" (Ramírez, Mil y una 275-76). Cada fotógrafo captura al sujeto en un instante concreto dentro de una sucesión de instantes, cada uno de los cuales manifiesta diferentes dimensiones de la persona en un momento concreto, más allá de una representación holística o más compleja, multidimensional, pero precisamente por eso más construida. Para Primoli, el recuerdo del sujeto vivo es un fantasma, un espejismo, mientras que el instante congelado, sin vida, es, paradójicamente, más verídico en la representación concreta de las múltiples dimensiones del personaje. Barthes hacía hincapié en la tensión del sujeto como imagen "móvil, sometida al traqueteo de mil fotos cambiantes" (42). Esta visión contrasta con los estados capturados y muertos de la foto concreta en Primoli, quien equipara el estudio fotográfico al laboratorio del "patólogo" (154). El fotógrafo Castellón convierte este instante congelado en un fin en sí mismo, lo cual deriva en su mórbido interés por fotografiar cadáveres, cuerpos inanimados en una imagen quieta que persiste en el tiempo, como invocando la persistencia del sujeto en una posición última e inmutable. Tal es el caso del retrato que Castellón toma subrepticiamente del cadáver desnudo de Turguénev mientras está siendo preparado para sus exequias y que le vale el destierro del elenco de fotógrafos respetables de la época. Castellón confiesa al final que su obsesión por ese momento obsceno (en el sentido etimológico del término: fuera de escena) se debe a que ha sido un "fotógrafo mediocre, un aprendiz toda la vida" (277). Su miedo a no dar la talla como artista ha generado una inclinación por lo mórbido como correlato de la objetividad.

Según Perkowska, las fotos de Castellón "visualizan la multiplicidad que habita al sujeto retratado, pero también exponen el ser del fotógrafo y las vicisitudes de su oficio" ("Fotografía"). El fotógrafo Castellón "es un ser múltiple y su obra es el mejor testimonio de esta superposición de identidades. Existe un joven aprendiz y fotógrafo profesional . . . un artista, perseguidor del misterio ... a veces un depredador . . . también oportunista y hasta colaborador". Esta multiplicidad, emparejada con su inclusión metaficcional como narrador de parte de la novela "desmitifica[n] también la neutralidad flaubertiana, que se revela como una encubierta interpretación o expresión ideológica del mundo".

Perkowska coincide con Ramírez en la existencia de los imperativos de un "oficio" formulados al extremo por el maestro Primoli 
(Perkowska, "Fotografía"; Ramírez "El nin̄o"), "[p]ueden estar desollando a tu propia madre, a tu propia hija, y tu deber es registrar el hecho" (Ramírez, Mil y una 154). Este imperativo tiene una repetición siniestra hacia el final de la carrera del discípulo cuando éste, ya anciano, registra el asesinato de su propia hija y su yerno a manos de los nazis (32). A través de este acto límite, el fotógrafo Castellón testimonia la reducción del colectivo judío a una condición infraciudadana. Extraídos a la fuerza del medio de vida familiar (la carnicería), el niño con los brazos en alto y los cadáveres tirados en el suelo en mitad del espacio público testimonian su condición liminar: son objetos de trata para el estado, que apenas tiene limitaciones legales para disponer sobre sus vidas. La fotografía de Castellón ilustra cómo el concepto de ciudadanía en el estado moderno está asediado por el fantasma del gobernado sin ciudadanía cuyas condiciones no se derivan de un mero infortunio económico sino de una exclusión programática que reduce a sujetos con determinadas características a mera existencia o vida-despojo (lo que Agamben llamó " nuda vita"). El testimoniaje del fotógrafo, por tanto, contrasta con la miopía de su padre biológico, Francisco Castellón, en sus aspiraciones de incorporación nacional: el estadista sueña con una articulación nacional al mismo tiempo que es incapaz de reconocer a parte sustancial de sus integrantes en figuras como Frederick y su sobrina. Castellón ve al primero como un rey-títere, igual que otros líderes europeos, mientras que a Catherine la viola en vez de cumplir con su compromiso matrimonial.

\section{Invocaciones: la recontextualización de héroes de ficción y horrores históricos en el espacio latinoamericano}

Como ya ha apuntado Perkowska, la foto de un muchacho con las manos en alto en primer plano, capturado desde un ángulo elevado, evoca asimismo y de manera muy directa la célebre foto del informe de Jürgen Stroop a Heinrich Himmler al final de la sublevación del ghetto de Varsovia ("Historia" 43-44). El rótulo del apotecario, "Capharnaüm" recuerda asimismo al pedante nombre del laboratorio de $\mathrm{M}$. Homais en Madame Bovary. De esa farmacia obtiene Teresa Segura un veneno que, de manera similar a Madame Bovary "se ... mete en la boca a puñadas, como si quisiera curarse de un hambre salvaje" (Ramírez, Mily una 50). 
Esa mezcla deliberada de episodios ficcionales con objetos paradigmáticos de la cultura occidental forma parte del juego de desmitificaciónmistificación que opera en la interrogación histórica de la novela. A este respecto, Perkowska enfatiza el "cuestionamiento posmoderno del documento ... materia de un juego irónico-paródico que socava su presunta veracidad y lo convierte en un elemento de ficción" en aras de la "deconstrucción posmoderna del documento histórico" ("Historias" 44, 45). Según Perkowska, "todo acto representacional, incluso el que dictan la compasión y/o la indignación, es una apropiación del sujeto representado y su exposición a la mirada de otros" ("Fotografía"). Sospecho sin embargo que el acto de apropiarse de una foto evocativa del holocausto con propósitos lúdicos y autorreferenciales conduciría la novela a un colapso ético que no parece coherente con la complejidad del tratamiento de la diversidad interior de objetos y ejecutores de la representación. El juego por medio del cual Ramírez ofrece objetos ficcionales que evocan por similaridad otros documentos históricos posibilita otras interpretaciones más allá del "desafío posmoderno al documento como baluarte del discurso histórico" (Perkowska, "Historia” 49).

Werner Mackenbach ha definido la obra de Ramírez como un recorrido desde la "literatura comprometida con la historia y la política hasta la historia como pretexto/pre-texto de una literatura que no ha renunciado a su afán de "contar lo no contado"' (Mackenbach 149). La relación entre historia y ficción en Sergio Ramírez ha sido ampliamente estudiada, asociándosele a una tendencia que en letras hispanas ha recibido la difusa denominación de "nueva narrativa histórica" (Menton $14)^{2}$. Esta "nueva narrativa" viene a ser lo mismo que Linda Hutcheon llamó, de una manera un tanto engorrosa pero mucho más precisa, "historiographic metafiction" (ix), y Elisabeth Wesseling, más genéricamente, "postmodernist historical novel" (vii). Hutcheon resaltaba como características del género: su tono paródico; la relación explícita del discurso con el material textual que lo fundamenta y lo constituye; la incorporación de material textual imaginario bajo guisa de autenticidad; la descentralización, atención al personaje subalterno o que testimonia desde los márgenes la acción del protagonista tradicional de la historia; presencia autorial; cuestionamiento de las capacidades del lenguaje para comunicar objetivamente y para filtrar y transformar la realidad empírica; $y$, por último, exageraciones en lo que respecta a su propia inestabilidad epistemológica (Hutcheon 285-94). Wesseling, por 
su parte, destacaba que este género literario no enfoca la historia desde una perspectiva didáctica, sino que se interesa más por la influencia del poder político en la creación de visiones de la historia. Esta nueva perspectiva conduce a técnicas autorreflexivas y versiones alternativas de la historia enmarcadas en una estructura ficticia caracterizada por cambios sorprendentes, exageraciones, distorsiones, alternativas, "overt falsification of history ... a as a strategy for unmasking the fictional construction of the past" (Wesseling 5).

Las características del género metahistórico se dan, en diverso grado, en Mil y una muertes, que Namorato posiciona "entre la ficción y la biografía novelada" (179). Mackenbach apunta que la obra de Ramírez trata sobre las relaciones complejas entre la realidad extraliteraria y la representación narrativa, entre la historia y la ficción, abunda en la reflexión metaficcional y autorreferencial, es representativa de "tendencias cambiantes en los discursos político-histórico-estéticos en el contexto de los procesos de cambio social que el istmo centroamericano ha vivido a partir de los años sesenta" (149). Como apunta Fernando Aínsa, la narrativa de Ramírez consiste en cuestionar quién exactamente está en posesión de la verdad, con el propósito de "buscar entre las ruinas una historia desmantelada por la retórica y la mentira al individuo auténtico perdido detrás de los acontecimientos . . . aunque parezca inventado, aunque en definitiva lo sea" (31).

Mil y una muertes abunda en la presencia de objetos textuales, materiales o visuales cuyo cuestionable status epistemológico fundamenta un acto imaginativo sumergido en la duda y la ambigüedad. Como apunta Perkowska, "Mil y una muertes se apoya en una impresionante investigación y documentación, en gran medida verificable, pero el ars combinatoria y la actitud lúdica del autor liberan los datos históricos de las ataduras referenciales" ("Historia" 45). Tal es el caso de las inserciones de los textos "El príncipe nómada" de Rubén Darío y "El fauno ebrio" de José María Vargas Vila (Ramírez, Mil y una 15-24, 159-73). Estos textos son espúreos, $y$, sin embargo, rescatan algunos manierismos estilísticos de sus pretendidos autores mientras que el aparato textual de la novela insiste en dar cuenta de ellos como auténticos; la entrada bibliográfica refiere a volúmenes lo suficientemente remotos y difíciles de obtener físicamente como para inspirar una posible sensación de autenticidad en el lector.

Además de estos objetos culturales, la novela abunda en otras mistificaciones históricas y literarias. La trama se sustenta sobre la 
"tradición leonesa" según la cual Francisco Castellón contribuyó a la famosa fuga de Napoleón III del fuerte de Ham con "dos cartuchos de oro" para sobornar a los guardas (Arellano 72), aunque su participación activa en el plan de fuga parece menos probable y no he encontrado constancia documental ${ }^{3}$. Otros historiadores hacen referencia al patrocinio de Napoleón III al hijo menor de Castellón, Jorge; a diferencia del hijo de la princesa Catherine, este es hijo legítimo, fracasa en sus estudios, y termina apuñalado en una reyerta tabernaria en León (Bolaños 177). El fotógrafo Castellón, por su parte, en una variación siniestra de la colaboración de su padre con el futuro emperador francés, ayuda al jefe del campo de concentración de Mauthausen. Ese jefe es identificado como "von Dengler" (Ramírez, Mil y una 262), cuando en la historia empírica ese dudoso honor le correspondió a Franz Xaver Ziereis.

Otro caso interesante de mistificación es la elucubración del rey Frederick sobre el origen miskito de Robinson Crusoe, obra clave en la formación del género novelístico en Occidente. Según Frederick, el náufrago en realidad se habría llamado Robin y su aventura se explicaría por su capacidad, como natural de la costa antillana, de sobrevivir en el medio natural (74-75). Así, lo que fue un suceso normal para una persona acostumbrada a estos lances se convierte, previa transfiguración en blanco, en hazańa y apología del ingenio de la civilización anglosajona (76-77). El rey miskito se representa intentando remedar esta transformación, ante la indiferencia de un Castellón amarrado a sus propios prejuicios $(75,78)$. La razón de ser de la disquisición de Frederick sobre el miskito Robin no radica tanto en su veracidad o no como en el corolario de que tal hecho no habría sido ninguna hazaña para alguien de "un pueblo en el que sus robinsones no hallan ninguna ciencia en sobrevivir todos los días de la caza y de la pesca, en perfecta soledad" $(76)^{4}$. Es irónico que el rey Frederick pretenda reposicionar una leyenda europea en un contexto no eurocentrista a la vez que él y sus hermanos aparecen tocados con todas las galas de la realeza europea. Por otro lado, esta alegoría trata de recordarle al político Francisco Castellón que sus manejos diplomáticos en busca de un reconocimiento de Nicaragua en el panorama europeo aspiran a hacer de la nación algo que no corresponde con sus realidades sociales y materiales más urgentes.

Combinan también ese carácter de mistificación y el juego con objetos culturales paradigmáticos dos enigmáticas fotografías. Como ya he dicho, la fotografía que atrae al personaje Ramírez por primera vez a la figura del fotógrafo Castellón evoca la infame imagen del informe 
de Jürgen Stroop tras el aplastamiento de la sublevación en el ghetto de Varsovia, que ha pasado a simbolizar el holocausto judío. La foto, sus personas desaparecidas, sin voz, el nińo que mira atemorizado con ojos perdidos más allá del marco de la cámara, aparecen reposicionados ante la lente del fotógrafo latinoamericano, como fantasmas que asedian insidiosos la conciencia occidental, recordándonos los aspectos más brutales de la experiencia moderna. Ello se conecta con la apocalíptica visión final que Perkowska llama "recuerdos del porvenir" ("Historia" 38): Castellón reaparece al término de la novela fotografiando un cadáver otra vez, como una persistencia fantasmal, cincuenta años después de su muerte. El paisaje evoca la catástrofe del huracán Mitch. La novela se cierra con esta visión dé pesadilla:

Entonces lo vi. Sobre el gris sucio del barro que definía todo el horizonte, estaba tendido el cadáver desnudo de un niño de unos tres años. A su derecha, un cerdo negro y flaco lo husmeaba, acercándose. (323)

La escena está inspirada en una foto real tomada para Associated Press en la devastación causada por el Huracán Mitch (Aranjua) a la vez que evoca la famosa foto de Kevin Carter en el transcurso de la hambruna somalí de 1993, ganadora del premio Pulitzer: un bebé malnutrido yace boca abajo sobre un suelo de tierra mientras, detrás suyo, un buitre lo contempla, esperando pacientemente su muerte. La evocación implícita de una imagen icónica producida desde el marco económico y cultural occidental en un marco que llame la atención sobre el destino histórico de Nicaragua (y, por extensión, del conjunto latinoamericano) resulta especialmente evocativas. En este punto, el carácter presumiblemente mistificador de la novela puede replantearse como una reclamación: devolver al recuerdo histórico a las víctimas de la devastación ocasionada por el Mitch o por cualquier tragedia natural en Latinoamérica o en cualquier país pobre o de riqueza pobremente distribuida.

A este espacio apocalíptico acude el fotógrafo voraz, representador compulsivo de desgracias y, a decir de Susan Sontag, su cómplice. En tanto que "disparar" la cámara viene a ser la sublimación del acto de disparar un arma de fuego, el acto de fotografiar constituye una suerte de "homicidio suave"; de hecho, en tanto que acto voyeurista, la fotografía anima tácitamente a que lo que ocurre siga ocurriendo, poniéndose así de relieve la duplicidad moral en el acto de testimoniaje (Sontag 14). Sin embargo, Ariella Azoulay observa que el examen de la imagen 
no puede limitarse a una relación entre representante y representado y que a pesar de la popularidad de esa visión casi violenta del contacto entre fotógrafo y objeto de representación, el acto de la fotografía en sí rara vez ocasiona una explosión de violencia. Azoulay plantea un modelo en que el sujeto ante el objetivo conoce la existencia de un público virtual ante el que se puede expresar una reclamación con contenido cívico (18). El acto de dejarse fotografiar cambia de significado, apunta a un espacio de relaciones políticas entre gobernados y gobernantes y a un reclamo: la exigencia de no ser gobernados en determinada forma (16-17).

Azoulay plantea la reinscripción social del sujeto fotográfico a través de la existencia de un "civil contrac̀t of photography" en el marco de una comunidad visual amplia con potestad de testimoniar la existencia al borde de la catástrofe como estado actual de aquellos que viven abandonados en los márgenes del sistema global (85). El contacto con el objetivo restablece las relaciones entre el sujeto y un espectador futurible más allá de las exigencias del poder o sistema vigentes. No excluye ni obvia la existencia de este poder, ni supone que el poder no pueda ejercer la censura, pero cuando éste interviene, cuenta solo como un actor más junto a los otros. El contrato civil de la fotografía asume que, al menos en principio, los gobernados pueden suspender brevemente el gesto del poder soberano en su intento de dominar las relaciones entre sujetos, dividiendo a los gobernados entre ciudadanos y no ciudadanos, integrados por el sistema o marginalizados por él (23). La fotografía desterritorializa la ciudadanía, extendiéndola más allá de las limitaciones tradicionales de la nación-estado. La fotografía plantea la posibilidad de un espacio político en el que la pluralidad de habla y acción se verían permanentemente actualizadas por la participación factible de todos los gobernados.

El fotoperiodismo tiende a representar la catástrofe como condición natural de aquellos que se encuentran en la periferia de los sistemas de intercambio globales, sujetos desposeídos de una condición ciudadana, con sus derechos y deberes, que se presupone propia del estado moderno, cuerpos de uso para la maquinaria económica pero reducidos a una mera vida-despojo. Sería posible entender el episodio final como cuestionamiento de la actitud del fotoperiodista con respecto al sujeto que aparece en su encuadre, una crítica a la representación de Latinoamérica como espacio de destrucción, a la improductividad futura de ese naciente "imperativo violento" en la representación de 
Latinoamérica (Sánchez-Prado 50) ${ }^{6}$. Por otro lado, la fotografía del cerdo ante el cadáver del niño testimonia la existencia-en-la-catástrofe. La catástrofe en ciernes es el estado concreto de los sujetos abandonados en los márgenes del sistema global, que asedia a múltiples poblaciones hoy en día, formadas por individuos cuya existencia es pasajera pero cuya condición al límite es permanente. Forzada a la precariedad, a esta población se le niega la posibilidad de exigir un cambio en su situación $y$, bajo estas condiciones, se permite a aquellos que puedan acudir en su ayuda hacerlo sólo en la medida en que preserven su existencia al límite de lo soportable, en el borde de la catástrofe (Azoulay 207). El estado puede estar interesado en ciertos bienes específicos que esta población no-ciudadana produce (cuerpos, trabajo, sexo, ciertas habilidades) pero este interés no es suficiente para alterar su estatuto precario. El nociudadano merece por parte del sistema tan sólo el cuidado que preserve su vida-despojo, que asegure la subsistencia mínima. Como la subsistencia mínima no siempre es suficiente, esta población vive arrojada al límite de la catástrofe (68). En esta condición sobrevive una porción importante de individuos sujetos a las imposiciones del sistema global, en una extensión globalizada de la explotación de la nación-estado característica del capitalismo industrial. A continuación veremos cómo la negativa de la casta gobernante a reconocer las condiciones marginales que ellos mismos imponen desestabiliza la coherencia y la viabilidad de sus aspiraciones y sueños de integridad nacional en el marco de la geopolítica global.

\section{El fantasma de la identidad política nicaragüense}

La conexión entre la foto de la hambruna somalí y la del huracán Mitch nos reconducen a Nicaragua. Mil y una muertes tiene un marcado tono europeizante. No sólo los personajes principales tienden a moverse hacia el viejo continente, sino que sus destinos se ven movidos en buena medida por aristócratas como Napoleón III o Luis Salvador de Austria, figuras representativas de regímenes imperialistas europeos.

El aspecto euroconvergente de la novela podría responder a cuestiones de política editorial. En una intervención en el congreso del IILI en Puebla (2008), Nicasio Urbina hizo hincapié en una paradoja en el reciente boom de las letras centroamericanas, que desde el último 
cambio de siglo hasta hoy ha venido dando visibilidad internacional a figuras como Gioconda Belli, Tatiana Lobo, Horacio Castellanos Moya o el propio Sergio Ramírez, por citar solo unas pocas. Urbina observaba que a medida que estos autores adquirían mayor reconocimiento internacional y su nombre pasaba a incorporarse a los planteles editoriales afiliados a los principales grupos mediáticos del mundo hispanoparlante, su temática tendía a deslocalizarse, hacerse menos propiamente centroamericana o, por lo menos, a atenuar la visibilidad de cuestiones políticas y sociales específicas de la región con el fin probable de volverse más digerible para un consumidor "internacional" (entiéndase: español). Así, a medida que la literatura centroamericana contemporánea se iba haciendo más visible, más se difuminaban las especificidades y urgencias locales que alimentaron su resurgimiento después de las guerras civiles del último siglo?.

Estas preocupaciones sitúan en un contexto más amplio a la vez que atemperan el entusiasmo de José Ángel Vargas, quien observa que Mil y una muertes "marca un notable cambio en cuanto a los espacios referenciales utilizados tradicionalmente por Ramírez", por lo cual "el ámbito nicaragüense ya no tiene una faceta primordial sino relativa. El escenario local y nacional ha sido resignificado" (25). Esta salida de un ámbito de "referencialidad muy definida" (Vargas 21) fue parcialmente corroborada por Ramírez en una entrevista donde declaraba querer "salirse del color local de la dictadura somocista" para explorar la "relación de Nicaragua con Europa" (Cortés 4). Puede decirse entonces que la ambición transatlántica de Mil y una muertes viene a ser el epifenómeno de ansiedades y anhelos más hondos que se manifiestan en su trama, especialmente la aspiración histórica de las naciones centroamericanas a adquirir una entidad, tomar cuerpo y autonomía en el escenario político internacional.

Empero, sería erróneo creer que la relevancia de Nicaragua ha desaparecido de Mil y una muertes. La propia nación nicaragüense como entidad política figura como fantasma de la América postcolonial, abandonada a los manejos políticos de otras potencias: chantajeada o ignorada por las potencias europeas que, sin embargo, necesitan abrir un canal a través de ella para acelerar el comercio internacional. Tal vez esa internacionalización de los temas de Ramírez observada por Vargas constituya la expresión externa de la ansiedad del diplomático Francisco Castellón al encontrarse con puertas cerradas, silencio y ninguneo 
mientras actúa como plenipotenciario nicaragüense en Europa, viviendo en posadas de viajantes comerciales y sufragando el viaje con sus propios fondos con la misión de reivindicar la existencia y materializar en la escena política a Nicaragua, "país declarado entonces inexistente" (53). Cuando Castellón protesta ante el ministro francés Guizot, este le responde con la anécdota de su visita al barón de Menier, que ilustra cómo los grandes poderes del occidente colonial se permiten ignorar la existencia y localización de los mismos territorios que explotan:

El barón de Menier, que posee plantaciones de cacao en Nicaragua, quiso mostrarme durante una velada de sobremesa en su castillo del Loire, dónde se situaba aquel territorio para mí desconocido por completo, y me llevó delante de un globo terráqueo. No podía encontrarlo, una mosca se había posado en el punto. Fue necesario ahuyentarla. (111-12)

Nicaragua no tiene entidad, o su entidad es metafóricamente inferior a la de una mosca revoloteando entre el mobiliario del despacho de un gran industrial europeo. En consecuencia, este fantasma de la escena internacional puede ser explotado a voluntad. Terminan de ilustrar esta anécdota los motivos africanos que decoran una caja de chocolates Menier (112): el barón explota cacao nicaragüense que la publicidad europea reimagina a través de evocaciones de sus nacientes aspiraciones coloniales en África. En contraste, en Nicaragua ningún político se atreve a contrariar las operaciones del barón francés, y mucho menos pedirle impuestos, evocando así usurpaciones y violencia económica históricamente más reconocibles como las de United Fruit Company y tantas otras corporaciones transnacionales hasta el día de hoy ${ }^{8}$.

Sin embargo, los pensamientos de Francisco Castellón terminan con una expresión llamativa: "Elefantes y papagayos, marfil y cacao, negros envueltos en túnicas e indios moscos coronados, todo daba igual" (112). La indiferencia exasperada de Francisco Castellón revela cómo el político liberal tampoco es capaz de salir del cerco creado por sus propios prejuicios. Las aspiraciones de integridad nacional de Francisco Castellón no pueden hallar plenitud cuando los representantes del estado son copartícipes en el ninguneo de los grupos de población más marginalizados y vilipendiados de Nicaragua y, por extensión, de Centroamérica. Por ejemplo, ante la aparición de la princesa Catherine, Castellón no ve en la mujer el objeto de un pacto previo, tampoco la acepta como una representación simbólica de un ente político (aunque 
este ente sea un mero protectorado) y ni siquiera es capaz de asumir la dignidad humana de la persona que aparece ante él. Francisco Castellón toma y utiliza ese cuerpo como sujeto abandonado por la ley y despojado de ciudadanía, mera vida, cuerpo de uso. Este episodio pone de relieve las deficiencias morales y políticas del jefe de estado. Más allá de las humillaciones simbólicas y presiones políticas procedentes de potencias extranjeras, su apropiación del Otro como objeto de uso manifiesta su incapacidad última para construir un cuerpo ciudadano integrado.

El desprecio del Castellón presidente en 1855 por la vida y bienestar de su prometida Catherine, reducida a sujeto gobernado y violable, contrasta con la preocupación de Castellón diplomático en 1846 por el destino de la belle Sabotière, la amante embarazada de Luis Napoleón. La incomodidad del futuro emperador ante la "pregunta ociosa, y repugnante al asunto grave" de su fuga reprocha al bisońo diplomático nicaragüense que todavía no comprenda que el ejercicio del poder en el marco político de las repúblicas liberales del siglo XIX radica en el valor de uso y disfrute de los súbditos, su capacidad de reducirlos a cuerpos gobernados (129). La voluntad de uso irrestricto de estos súbditos por parte de los hombres de estado contrasta con el proyecto del canal de Nicaragua, objeto-fetiche donde se concentran las aspiraciones de los políticos e intelectuales de la nación. El canal es el objetivo que dará entidad y razón de ser a la joven república, lo que otorgará integridad física, visibilidad, a este fantasma político. Ejemplo de este anhelo de identidad y razón de ser son las proyecciones del tutor del fotógrafo Castellón, el maestro Leonard, personificación afrancesada de la antigua capital nicaragüense, León, a la que se imagina como la futura Constantinopla de América, un puente entre los mundos europeo y americano (232). El maestro Leonard representa a esa intelligentsia latinoamericana que preconizó los grandes proyectos orgánicos de urbanismo y gestión territorial. Sin embargo, esa promesa, esa proyección fantasmagórica es precisamente lo que convierte a Nicaragua en objeto de la rapacidad de mercenarios extranjeros como William Walker que, los cuales se aprovechan de las contiendas civiles que asolan y habrán de asolar a esta u otras repúblicas americanas.

Las proyecciones de la ciudad letrada degeneran en sus supersticiones: el maestro Leonard termina sus días intentando comunicarse telepáticamente con Napoleón III, según técnicas ocultistas en boga en la época (233). El propio canal, pues, se convierte en el referente 
fantasmal de comunicaciones imaginarias. La decepción y el fracaso individual de los personajes de Mil y una muertes es un epifenómeno de un fracaso histórico de alcance mayor representado en la reaparición del fotógrafo al final de la novela. Su visión combina la nostalgia de las aspiraciones del pasado con una visión final apocalíptica:

\begin{abstract}
Ningún trazado napoleónico partía la nueva Constantinopla, bendecida por el trazo del canal por Nicaragua, ningún bullicio de marineros en los barrios de putas exhibidas en vitrinas como las de la Reeperbahn en Hamburgo, ningún mugido de barcos en la noche rompiendo los bancos de niebla, ningún tañido de las campanas de las boyas reponiendo al de las viejas iglesias, como mi padre el iluso habia ambicionado, y tras la cortina de lluvia sólo vi baldíos donde crecía feraz la cizaña, paredes derruidas a medias, y más cizańa encima de los portales quemados, ruinas de la más reciente de las guerras civiles que aparecian frente a mis ojos al fulgor de los faros del vehículo, y por fin se hundían en la oscuridad. (321-22)
\end{abstract}

\title{
A modo de conclusión
}

Mil y una muertes es una novela compleja donde se combinan la peripecia individual con la historia del desarrollo de los estados-nación postcoloniales, se entrecruzan y entran en tensión lo estético con lo ético, lo político con lo biológico. Dos entidades fantasmales rigen su trama: la voz de ultratumba del artista frustrado, el fotógrafo Castellón, y Nicaragua como ente que busca incorporarse como miembro de pleno derecho en la comunidad de naciones. Ambas entidades convergen en la apocalíptica imagen final del fotógrafo que no puede dejar de disparar su cámara mientras un cerdo se aproxima a un despojo humano con intenciones de devorarlo y que termina arrollado por un alud de lodo. Esta imagen se puede interpretar en clave alegórica, como una advertencia contra la tentación contraproducente de enquistarse en visiones de lo latinoamericano como sitio natural de lo apocalíptico. Por otro lado, la novela constituye una compleja exploración de las limitaciones y posibilidades del fotógrafo, artista o cronista. El fotógrafo Castellón es una figura contradictoria con la fiebre obsesiva de producir un mero registro visual objetivo que a la vez aspira a determinarse como arte. La ambigüedad moral del discurso de la novela entre lo mórbido y lo testimonial, sin embargo, alumbra la condición espectral, liminar, de 
la infraciudadanía de los cuerpos a la merced del estado situados en los límites de la catástrofe que el arte fotográfico está en una posición única para documentar.

Las frustraciones artísticas de Castellón son eco de una frustración simbólica más amplia, la de Nicaragua como proyecto nacional frustrado, cuyos líderes buscan crear un cuerpo ideal a través de una sección, un corte, la creación de un canal interoceánico que abra el país al comercio y la inversión internacionales. Estas ambiciones no logran hallar acomodo en los designios de los imperios occidentales y la condición neocolonial desemboca, siglo y medio después, en el escenario apocalíptico después del Mitch: un país asolado por pugnas intestinas e intervenciones exteriores que no termina de alcanzar una normalidad político-económica que le permita enfrentarse a una catástrofe natural con eficacia.

Ambos fantasmas, el fotógrafo y la nación nicaragüense, han sido engendrados por Francisco Castellón, diplomático y presidente de la nación, una figura que se nos representa como un hombre de estado idealista y con aspiraciones, al igual que el rey Frederick, pero también evasivo, intransigente y (desde nuestra perspectiva contemporánea) moralmente limitado por hondos prejuicios. Esta figura viene a encarnar las contradicciones de cualquier proyecto de modernidad o integración nacional asentado sobre las bases de la exclusión.

\section{Santa Clara University}

\section{NOTAS}

* Agradezco al Decano del College of Arts and Sciences de Santa Clara University la beca que me permitió leer una versión inicial de este trabajo en el I Congreso "Fantasmagorías" en la Universidad Iberoamericana (México) en octubre de 2012.

${ }^{1}$ Ver también Sontag (4).

${ }^{2}$ Véanse también Perkowska, Historias hibridas cap. 1 y Rodríguez.

${ }^{3}$ Darío lamenta que las memorias del diplomático Crisanto Medina sobre la gestión del canal de Nicaragua no elaboren sobre "las relaciones estrechas que ligaron al monarca francés y al ministro nicaragüense Castellón” (93), mientras que el historiador Pío Bolaños da por hecho que Castellón financió la fuga del futuro emperador (177). Esta 
"tradición leonesa" podría haberse originado en un opúsculo propagandístico de un tal F. T. Briffault. Según Briffault, una petición de "a captain of the East Indies [sic]" para entregarle a Luis Napoleón "a message from the government of Central America [sic] respecting the Canal of Nicaragua" fue interpretada por la inteligencia policial como el prolegómeno de un plan de fuga (Briffault 80-81).

${ }^{4}$ Generalmente se atribuye la inspiración de Robinson Crusoe al marinero escocés Alexander Selkirk.

${ }^{5}$ El propio Ramírez ya explicitó esta conexión en su artículo "El niño, el cerdo y el buitre".

${ }^{6} \mathrm{La}$ expresión de Sánchez-Prado parafrasea el concepto de "magic realist imperative" de Sylvia Molloy (189ss.).

${ }^{7}$ El fenómeno subrayado por Urbina no es nuevo en el ámbito de Latinoamérica en general. Ya es famoso el (ambiguo) lamento de Fuguet en el prólogo a la antología $\mathrm{McOndo:} \mathrm{"Si} \mathrm{uno} \mathrm{es} \mathrm{un} \mathrm{escritor} \mathrm{latinoamericano} \mathrm{y} \mathrm{desea} \mathrm{estar} \mathrm{tanto} \mathrm{en} \mathrm{las} \mathrm{librerías}$ de Quito, La Paz y San Juan hay que publicar (y ojalá vivir) en Barcelona. Cruzar la frontera implica atravesar el Atlántico" (11). A principios del cambio de siglo, el suplemento cultural de Clarin observaba las dificultades de adquirir la obra de los autores argentinos vivos con mayor reconocimiento internacional en la propia Argentina (Molina). Tampoco se extraña nadie hoy cuando en los congresos literarios alguien hace referencia a la "alfaguarización" de las letras latinoamericanas, neologismo acuñado en una revista académica online mexicana (Barrera Enderle).

${ }^{8}$ Importantes corporaciones extranjeras que explotaron los recursos nicaragüenses con amplios incentivos por parte del somocismo fueron la canadiense McIntyre (minera) y las estadounidenses Robinson (maderera) y Texaco, hoy Chevron (petrolífera). A día de hoy, bajo el acuerdo CAFTA-DR, las inversiones extranjeras en servicios turísticos y en las zonas francas para la exportación gozan de una exención fiscal de diez ańos, con cinco adicionales en ciertas condiciones, amén de otros beneficios fiscales (Cámara de Comercio Americana de Nicaragua y PRONicaragua 76-77, 80).

\section{OBRAS CITADAS}

Abraham, Nicolas, y Maria Torok. L'écorce et le noyeau. París: Flammarion, 1978. Impreso.

Agamben, Giorgio. Homo Sacer. El poder soberano y la nuda vida. Trad. Antonio Gimeno Cuspinera. Valencia: Pre-Textos, 2010. Impreso.

Ainsa, Fernando. "La reescritura de la historia en la nueva narrativa latinoamericana". Cuadernos Americanos 4.28 (1991): 13-41. Impreso.

Aranjua, Rodrigo. "En el gran cementerio que hizo el huracán 'Mitch' en Posoltega ..." El Nuevo Diario 3 nov. 1998. Red. 6 nov. 2013. 
Arellano, Jorge Eduardo. Diccionario de autores nicaragüenses. Managua: Biblioteca Nacional Rubén Dario, 1994. Impreso.

Azoulay, Ariella. The Civil Contract of Photography. New York: Zone Books, 2008. Impreso.

Barrera Enderle, Víctor. "Entradas y salidas del fenómeno literario actual o la 'alfaguarización' de la literatura hispanoamericana". Sincronia. A Journal for the Humanities and Social Sciences 7.22 (2002). Red. 29 ene. 2014.

Barthes, Roland. La cámara lúcida. Ensayo sobre la fotografia. Trad. Joaquim SalaSanahuja. Barcelona: Paidós, 1990. Impreso.

Bennett, Andrew, and Nicholas Royle. An Introduction to Literature, Criticism and Theory. 3rd ed. Harlow: Pearson Longman, 2004. Impreso.

Bolaños, Pío. "Napoleón III y el nicaragüense licenciado Don Francisco Castellón". 1950. Obras de Don Pío Bolaños. Vol. 2. Managua: Fondo de Promoción Cultural Banco de América, 1977. 171-82. Impreso.

Briffault, F. T. The Prisoner of Ham: Authentic Details of the Captivity and Escape of Prince Napoleon Louis. Londres: T. C. Newby, 1846. Archive.org. Red. 6 nov. 2013. Cámara de Comercio Americana de Nicaragua; PRONicaragua. Doing Business in Nicaragua 2012-2013. Managua: AMCHAM, 2012. Red. 11 Nov. 2013

Carter, Kevin. "Starving Sudanese Girl". New York Times 26 marzo 1993. Red. 7 oct. 2014.

Colín, José Juan. “'Para no desperdiciar mi vida sin escribir'. Entrevista con Sergio Ramírez Mercado". Letras Hispanas 2.1 (2005): 100-05. Impreso.

Cortés, Carlos. "Flotante: Las mil y una vidas de Sergio Ramírez". La Nación, Suplemento Áncora 5 dic. 2004: 4. Impreso.

Darío, Rubén. "La cuestión de los canales". La caravana pasa. Ed. Gunther Schmigalle. Vol. 4. Managua: Academia Nicaragüense de la Lengua, 2004. 79-102. Impreso.

Derrida, Jacques. Spectres de Marx: L'état de la dette, le travail du deuil et la nouvelle internationale. Paris: Editions Galilée, 1993. Impreso.

Fuguet, Alberto, y Sergio Gómez. McOndo. Barcelona: Grijalbo Mondadori, 1996. Impreso.

Gámez, José Dolores. Historia moderna de Nicaragua. Complemento a mi Historia de Nicaragua. Managua: Banco de América, 1975. Impreso

Gordon, Avery. Ghostly Matters. Haunting and the Sociological Imagination. 2nd ed. Minneapolis: U of Minnesota P, 2009. Impreso.

Hutcheon, Linda. A Poetics of Postmodernism: History, Theory, Fiction. New York: Routledge, 1988. Impreso.

Mackenbach, Werner. "Historia y ficción en la obra novelística de Sergio Ramírez". Iberoamericana 5.19 (2005): 149-66. Impreso.

Medina, Crisanto. El canal interoceánico y el porvenir de Centro-América. Madrid: Imprenta de Hernando y Compañía, 1898. Impreso.

Menton, Seymour. La nueva novela histórica de la América Latina, 1979-1992. México, DF: Fondo de Cultura Económica, 1993. Impreso.

Molina, Daniel. "Nuestros Libros Extranjeros". N. Revista de Cultura. Suplemento de Clarin 16 (2002). Red. 6 nov. 2013. 
Molloy, Silvia. "Latin America in the U.S. Imaginary". Ideologies of Hispanism. Ed. Mabel Moraña. Nashville, TN: Vanderbilt UP, 2005: 189-200. Impreso.

Namorato, Luciana. "Mil y una muertes: Un personaje en la confluencia de la historia y la ficción". Sergio Ramirez. Acercamiento crítico a sus novelas. Ed. José Juan Colín. Guatemala: F\&G Editores, 2013. 175-96. Impreso.

Perkowska, Magdalena. "Fotografía, literatura y ética en Mil y una muertes de Sergio Ramírez". Otro Lunes 3.9 (2009). Red. 6 nov. 2013.

"Historia, fotografía y metaficción en Mily una muertes, una novela fotográfica de Sergio Ramírez". Itinerarios 9 (2009): 35-51. Red. 6 nov. 2013.

Historias hibridas: La nueva novela histórica latinoamericana (1985-2000) ante las teorías postmodernas de la Historia. Madrid: Iberoamericana, 2008. Impreso.

Punter, David. "Spectral Criticism". Introducing Criticism at the 21st Century. Ed. Julian Wolphreys. Edinburgh: Edinburgh UP, 2002. 259-78. Impreso.

Ramírez, Sergio. Mil y una muertes. Madrid: Alfaguara, 2004. Impreso.

- "El nińo, el buitre y el cerdo". La insiginia (5 sept. 2006). Red. 30 oct. 2013.

Rodríguez, Sheila Kraybill. "Asalto desde las sombras. La nueva novela histórica y la obra reciente de Sergio Ramírez". Tesis doctoral. Temple U, 2005. Red. ProQuest Dissertations and Theses: The Humanities and Social Sciences Collection. 18 ene. 2013.

Sánchez-Prado, Ignacio. "Amores Perros: Exotic Violence and Neoliberal Fear". Journal of Latin American Cultural Studies 15.1 (2007): 39-57. Impreso.

Sontag, Susan. On Photography. New York: Farrar, Straus and Giroux, 1977. Impreso. Stroop, Jürgen. "Revuelta del ghetto de Varsovia". Mayo 1943. Wikimedia Commons. Red. 18 ene. 2013.

Urbina, Nicasio. Nueva novela centroamericana y los medios de producción literaria. XXXVII Congreso del Instituto Internacional de Literatura Iberoamericana, 24 jun. 2008, Puebla, México. Impreso.

Vargas Vargas, José Ángel. "Mil y una muertes: Nuevos referentes de la novelística de Sergio Ramírez”. Revista Comunicación 15.1 (2006): 20-25. Impreso.

Villaurrutia, Xavier. "Epitafios”. Nostalgia de la muerte: poemas y teatro. Ed. Rosa García Gutiérrez. Madrid: Hiperión, 2006. 96. Impreso.

Wesseling, Elisabeth. Writing History As a Prophet: Postmodernist Innovations of the Historical Novel. Philadelphia: John Benjamins, 1991. Impreso.

Palabras clave: literatura de Nicaragua, Sergio Ramírez, Mil y una muertes, novela histórica, metaficción historiográfica, fantasma, espectro, fotografía, nación e identidad en literatura, modernidad, Centroamérica, Francisco Castellón, canal interoceánico.

Fecha de recepción: 12 noviembre 2013

Fecha de aceptación: 27 enero 2014 
Copyright of Revista de Estudios Hispanicos is the property of Washington University and its content may not be copied or emailed to multiple sites or posted to a listserv without the copyright holder's express written permission. However, users may print, download, or email articles for individual use. 